\title{
Importance of Architecture and Planning of Kanchipuram and the Dynamics of Implementing Architectural Restoration
}

\author{
Thirumaran K and Renganathan R \\ Department of Architecture National Institute of Technology, Trichy
}

Email: renganathan.r@gmail.com

ARTICLE INFORMATION

Received: May 20, 2019

Revised: June 13, 2019

Accepted: June 29, 2019

Published online: July 11, 2019

Keywords:

Urban heritage, Vernacular Architecture, Context, Social Capital, Block, Tissue

DOI: http://doi.org/10.15415/cs.2019.71004

\begin{abstract}
The importance of traditional architecture and planning of Kanchipuram is expressed through a set of objective and subjective map based indicators. The analysis is done at the block level. The results brings out values expressing the epitome of the traditional architecture and planning. The paper presents the map based analysis of the traditional core. The map based analysis perceives changes in the tissues of the study area. The paper emphasizes the importance of social activities as a key to good urban life. The importance of social activities in par with physical component holding it is also presented. A subjective note on climatic considerations at the block level is given based on observations. To compliment conservation measures, a feasibility study to revamp vernacular elements in the modern facades of the city is probed. Stated preference survey method was adopted for the feasibility study. Emphasis is given to public participation and professional involvement in the process of planning and implementing conservation measures. The measures shall realize economic development and life processes. Further certain morale ethics involved in the process methods of planning is discussed. Though the changes are high; the city upholds bright quos towards conservation pertaining to acceptance of traditional aspects and the urge for socialization.
\end{abstract}

\section{Introduction}

'Humanizing the city by placing the individual at the center of public policy' (UNESCO's message). People's behavior and their interaction are intricately shaped by their culture. In other words culture is what makes each person who they are, how they live and how they define happiness (Minya Yang, 2016). Therefore heritage is not only a testimony of the past urban and architectural development but inextricably linked to intangible heritage evolving from the way people lived. Hence there is a need to promote heritage with a cultural base which would enrich the present with the past. The challenge therefore is integration of heritage needs with longer needs of socio economic development in such a way that heritage values are compromised to minimal possible extent (Rohit, 2013). Any initiative or project under heritage conservation involving a single building or a group of building should be the outcome of the needs and interest of the key proponent. The key proponent could be the user, owner or a group of local residents. The professionals involved in carrying out the project should consider their needs and interests. Their need and interests would directly consist the social, cultural and economic considerations required for the project.
The focus of heritage conservation would be to preserve and upgrade the physical component. However this professional intervention of conserving the physical component is successful only if there is a wholesome point of view of life which the physical component upholds. Professional intervention would be successful if the conservation measures are an outcome of the realized felt needs of the people using, owning and having a key stake of the physical component. The social dimensions to be considered in heritage conservation is the necessary factor which must have shaped the physical domain. Hence it is pointless to conserve only the form without any considerations to the context. The social dimensions are a major constituent of the context along with climatic considerations.

The aim of the paper is to bring out the values behind traditional architecture and planning of Kanchipuram which are facing an array of changes and to probe the feasibility of conserving them. The paper also attempts to discuss conceptual approach aspects relevant to professional involvement and social acceptance towards implementing the conservation measures.

The values presented are physical, social responsiveness and climatic responsiveness. The values of the physical design 
are presented by a block analysis using certain indicators. Social responsiveness is subjectively discussed using area statements, subjective observations at par with certain indicators and the survey results. The climate responsiveness is also discussed observationally. It also portrays and perceives the changes happening due to modernization. The change happening to the settlement is perceived by the tissue analysis. Here the changes to happening at the plot level is objectivized.

After presenting the values the paper aims at representing the feasibility of adapting the vernacular elements in the modern facades of Kanchipuram. This method of conserving, regenerating and retrofitting the facades would be a prelude to further sensitization and preservation of other dimensions of architecture and space planning. This forms a probation complementing the implementation of the conservation measures. Preferences for key vernacular elements are probed in the survey and preference towards socializing and its dynamics are also probed. Kanchipuram is a Heritage city with a number of temples and traditional settlements. It was the capital of the Pallava Kingdom. Historically it is known for its pioneering educational trusts. It was known as "Kalviyil Sirantha Kanchi". It was called as "Nagareshu Kanchi" by Poet Kalidas ( $4^{\text {th }}$ century) meaning the best among cities. It is also one of the seven important holy cities of India. (Ayodhya, Mathura, Haridwar, Varanasi, Kanchipuram, Ujjain and Dwarka). The stock of residences around Ekambaraeshwarer temple and the Varathraja Perumal Temlpe had a good number of traditional houses intact. The above two zones are called as Periya Kanchi and Chinna Kanchi respectively. They were taken up for probation along with the connective spine of $1.7 \mathrm{~km}$. This spine is the traditional processional route during temple functions. The zones around the temples are predominantly residential and the processional route is predominantly commercial.

\subsection{Social Interaction and Physical Components}

Social activities represent social dimensions to a greater general extend with relevance to the physical.

Social activities are all the activities that depend on the presence of others in public spaces. Social activities include children at play, greetings and conversations, communal activities of various kinds and finally passive contacts (Jan Gehl, 1980).

The social activities which were indigenous in all its types as expressed above happened in the public spaces and streets of vernacular settlements of India. A step further these activities were allowed as a part of the households front yard (thinnai - a verandah space suited for sitting).
There is a meaningful relationship between social interaction and physical components (Ahmad, Kashan, 2016). It is of paramount importance to understand the relationship between social interaction and physical component which support it. The two factors of the physical component influence the social interaction. They are accessibility and physical quality of the spaces (Yuliastuti, Sukmawati, Purwoningsih, 2015).

\subsection{Importance of Building Facades}

Apart from the public spaces, semi-public spaces and circulation aspects of the urban street, the building façade is also the key member in the physical component. Historical building facades are important as they impose impact on the images of the district (Askari, Dola, 2009). The building façade or the building frontage is the influencing factor in the memories of the users of the street. The users perceive the elements of the façade. Consistency of color, details and composition of the physical elements of the building façade determine the visual richness of the streetscape (Tucker et al, 2004).

\subsection{Study at the block level in Periya Kanchi and Chinna Kanchi}

The paper attempts to bring out the value of traditional planning and architecture of Kanchipuram. The valuing in done with a set of recent map based indicators. Certain indicators are used objectively and certain indicators are used subjectively. The indicators used objectively are variance, block density and fragmentation. The paper refers to the work of Xin li et al, 2016 for the usage of such indicators in analyzing urban fabric. The general definition of variance suggest a quality of being different. The paper attempts to study variance based on the building foot print sizes in each block. Density is defined as a measure of compactness. The paper examines the density of building foot prints of each block.

Fragmentation is a measure of fineness and homogeneity. It is an ecological indicator used in this context to interpret the fragmentation of building footprints in each block. Other indicators used subjectively in the discussions are softness, social width, sedibility, detractors and façade continuity.

\section{Methods}

The map based analysis was carried out for the entire study area including the central processional route. The map based analysis were carried out using Auto Cad. Tissue dimensions were analyzed in the mapping exercise. 
A block level analysis was carried out for forty blocks in both Periya Kanchi and Chinna Kanchi. Data extracted from the digitized autocad drawings were analyzed in MS Excel and the three indicators mentioned earlier were calculated. The feasibility of adapting vernacular elements in the facades of modern households was obtained through a preference survey with a sample size of 32.The residences within the core area were chosen randomly for the survey. The preference survey was done in the method of stated preference method. According to Wardman (1987), the origins of Stated Preference methods can be traced back to studies in the area of mathematical psychology in the 1960's. This work looked at how individuals combined information in the process of decision making. Stated preference method was first used in experimental economics. It was consequently used in market oriented research and transportation research. This method can be used in hypothetical situations. Existing and non-existing alternatives can be considered. There could be extensive range of attribute levels. There could be one or more responses from the individual. Hence this method suited the need for conducting a survey for a futuristic intervention hence was chosen for this component of the study. Seven parameters expressing the preferences towards vernacular elements were analyzed using a multiple correlation matrix. The degree of preference was obtained as the result of the analysis.

\section{Results}

\subsection{Tissue Analysis}

A tissue analysis of the entire study area was carried out to perceive the extend of modifications at the plot level. The entire study area was divided into five zones. The length and breadth of plots were measured and averaged for every zone. The focus of the analysis was to find the narrowness in the plots. Mayamatam an ancient treatise in architecture of Tamilnadu puts forth the length of the plot to be a number of times its width. Hence the narrower plots were considered to be unaltered in the analysis.

It was evident that in the zone 1 and 5 which were Periya Kanchi and Chinna Kanchi respectively the plots were narrower and deeper than the plots in the rest of the study area. These residential areas are agraharam type of houses with deep plots. The tissues in these zones were still intact though there are a few changes. From the household survey it was evident that $11 \%$ of the tissues in Periya Kanchi were modified and $89 \%$ was unaltered. In Chinna Kanchi there was no change in tissue. In the central processional route (zone 2, 3, 4) the plots were less deep and were not narrow. This shows that commercialization has converted all the tissues in these zones. This was evident in the observations made in the satellite image
Table 1. Average dimensions of survey plots/tissues in various zones within the study area (Author, 2018)

\begin{tabular}{lll}
\hline Zones & Average length & Average breadth \\
\hline Zone 1 & 51.6 & 8.2 \\
Zone 2 & 23.8 & 11.9 \\
Zone 3 & 39.2 & 10.2 \\
Zone 4 & 34.7 & 13.3 \\
Zone 5 & 37.2 & 7.8 \\
\hline
\end{tabular}

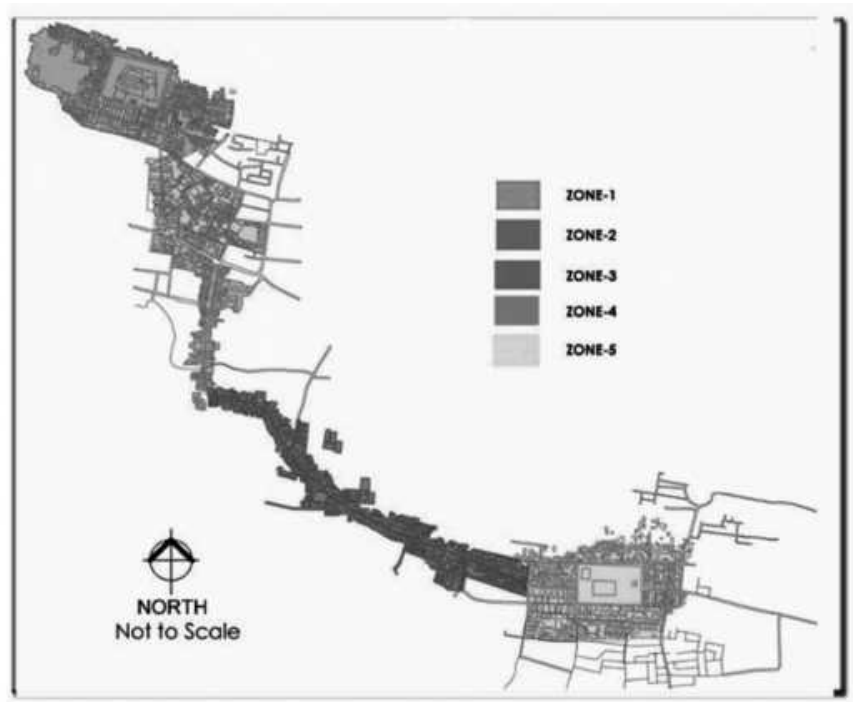

Figure 1. Map indicating - Tissue Analysis of the study area in Kanchipuram (Source: Author, 2018)

\subsection{Block Analysis}

There were 23 blocks in Periya Kanchi and 17 blocks in Chinna Kanchi.Each of the 40 blocks were mapped and analysed. The range of block area varies from $504464 \mathrm{sqft}$ to 26786 sqft. The average percentage of open space in each block was $23 \%$. The average percentage of semi private socializing space in each block was $13 \%$ i.e the 'thinnai' space in front of the houses. The range of number of houses in each block varies from 188 to 14 . The range of the average foot print size in each block varies from 3888 sqft to 924 sqft. Each block was valued using three quantitative indicators variance, block density and fragmentation.

Variance $=\frac{\varepsilon \frac{\sqrt{S i-S}}{N-1}}{S} \mathrm{Si}=$ Foot print area, $\mathrm{S}=$ mean,

$\mathrm{N}=$ Number of foot prints Block Density $=\frac{\varepsilon S i}{S b} S i=$ Foot print area, $S b=$ Area of
block 
Fragmentation $=1-\frac{4 \sqrt{S i}}{P} \mathrm{Si}=$ Foot print area,
$\mathrm{P}=$ Perimeter

The value of block density of each block indicates that $53 \%$ of the blocks had a density of more than 0.8 and $98 \%$ of the blocks had a density of more than 0,5 . The results of variance for each block varied with a range from 0.022 to 0.011 . The results of fragmentation suggests that $98 \%$ of the blocks had a value less than 0.5 . A covariance analysis was carried out among the various indicators. A positive covariance was observed between variance and fragmentation (5.02).A negative covariance was observed between variance and block density (-7.79).A negative covariance was observed between block density and fragmentation $(-0.06)$.

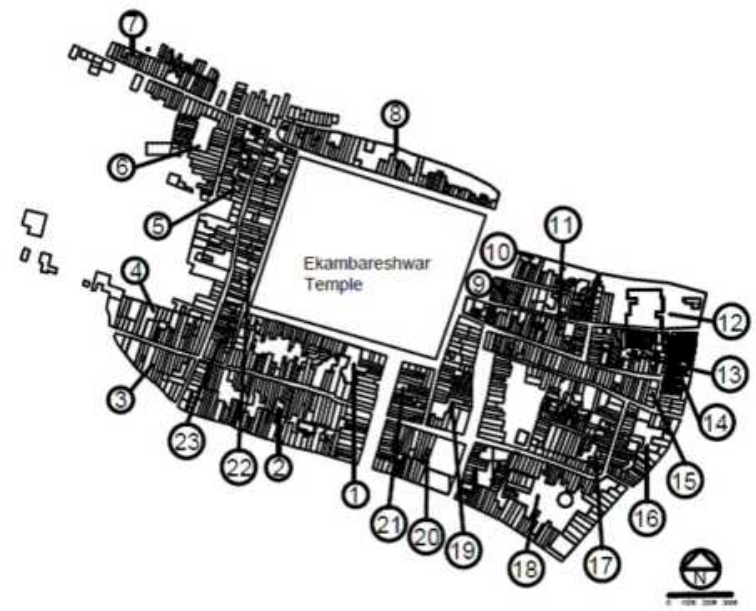

Figure 2. Map indicating - Plan of 23 blocks at Periya Kanchi (Source: Author, 2019)

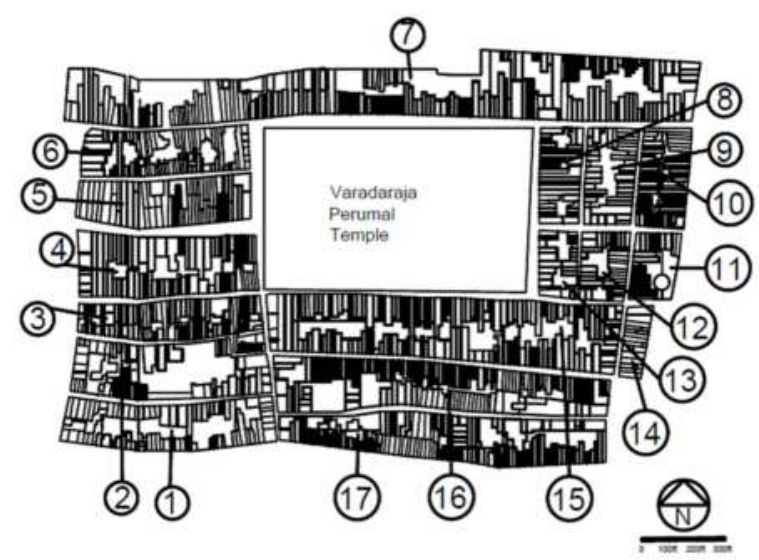

Figure 3. Map indicating - Plan of 17 blocks at Chinna Kanchi (Source: Author, 2019)

The above figure indicates a typical vernacular residence at Chinna Kanchi.It is characterized with a thinnai (semi private verandah for socializing), balcony on the first floor, large voluminous living room and a courtyard at the rear. The plan of the house is linear with a number of private rooms. Though the elements are common in all the houses their configuration varies from house to house. It expresses clearly the phenomenon of differentiation in the plans.

\subsection{Dynamics of Implementation}

The study thus paves way to establish the priorities for conservation. Further a preference survey was carried out to get the people opinion on adapting vernacular elements in facades of modern residences of Kanchipuram. Among the households surveyed $78 \%$ of them preferred a compounded residence with front setback as against a façade which abuts

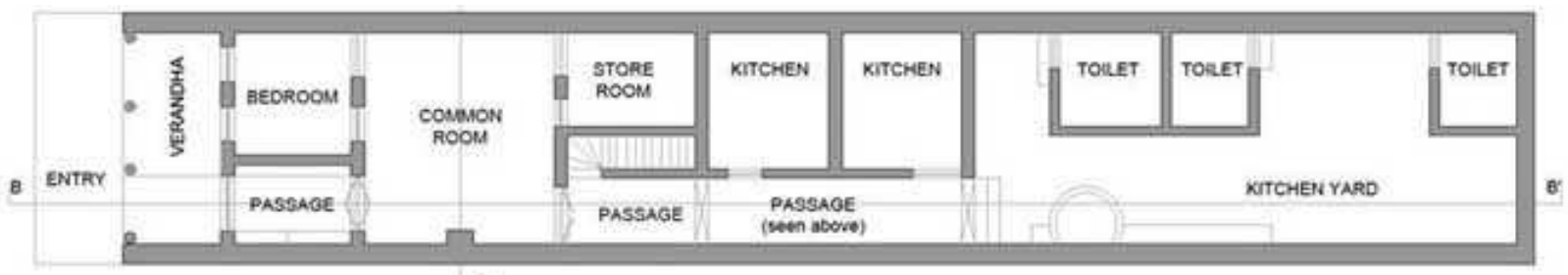

Figure 4. Graph showing block density of 40 blocks (Block 1-23 - PeriyaKanchi, Block C1 to C17 -ChinnaKanchi) (Source: Author, 2019)

the road. The reasons for such preferences were predominantly the need for a garden and car parking. Security reasons and growing pets were minor reasons. The degree of socializing of the households were probed. $39 \%$ of the respondents socialized with 3 to 6 households in their neighborhood, where as 25\% socialized with 6 to 9 houeholds. Hence the socializing fervor of people with neighbours has not come down with reference to their preference for a compounded house. Around $94 \%$ of the people preferred individual parking as against common parking. The preference location of the garden space was in front and on all four sides. The preference for vernacular elements was probed for all the people irrespective of their choice for a compounded residence.

\subsection{Feasibility of Adapting Vernacular Elements in the Modern Facades}

As another step towards implementation the paper attempts to explore the feasibility of adapting vernacular 


\section{BLOCK DENSITY}

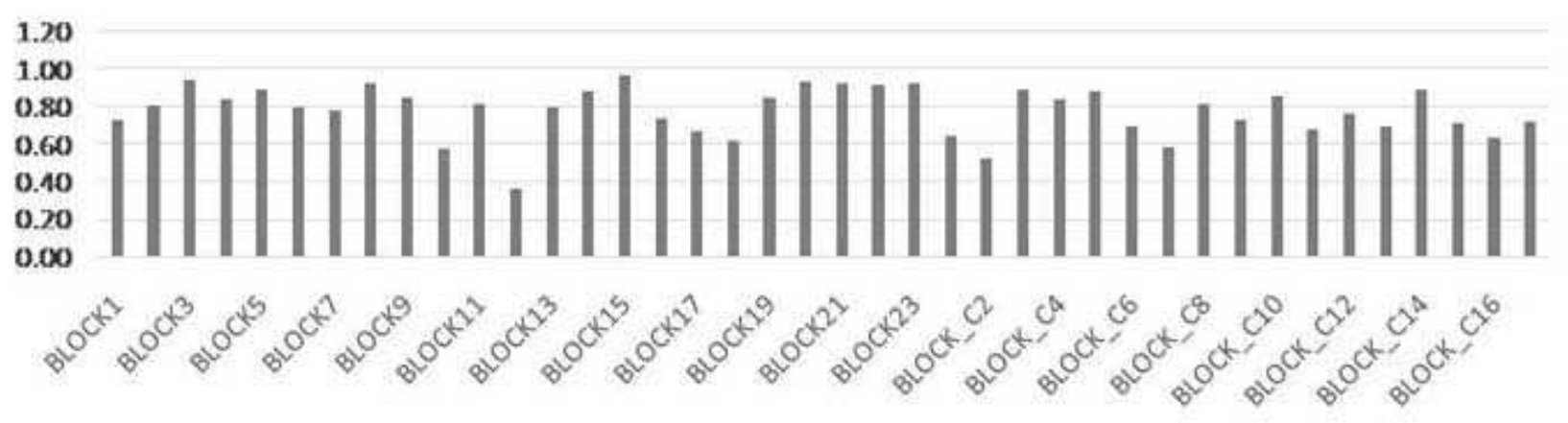

Figure 5. Graph showing Variance of 40 blocks (Block 1-23 - PeriyaKanchi, Block C1 to C17 - ChinnaKanchi) (Source: Author, 2019)

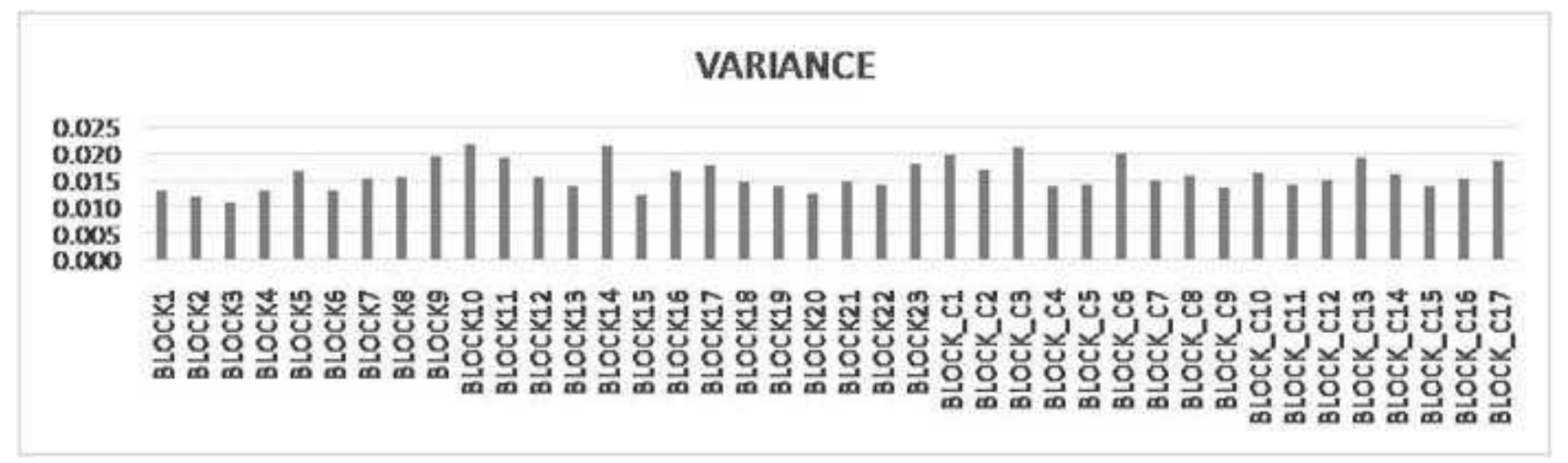

Figure 6 Graph showing Fragmentation of 40 blocks (Block 1-23 -PeriyaKanchi, Block C1 to C17 -ChinnaKanchi) (Source: Author, 2019)

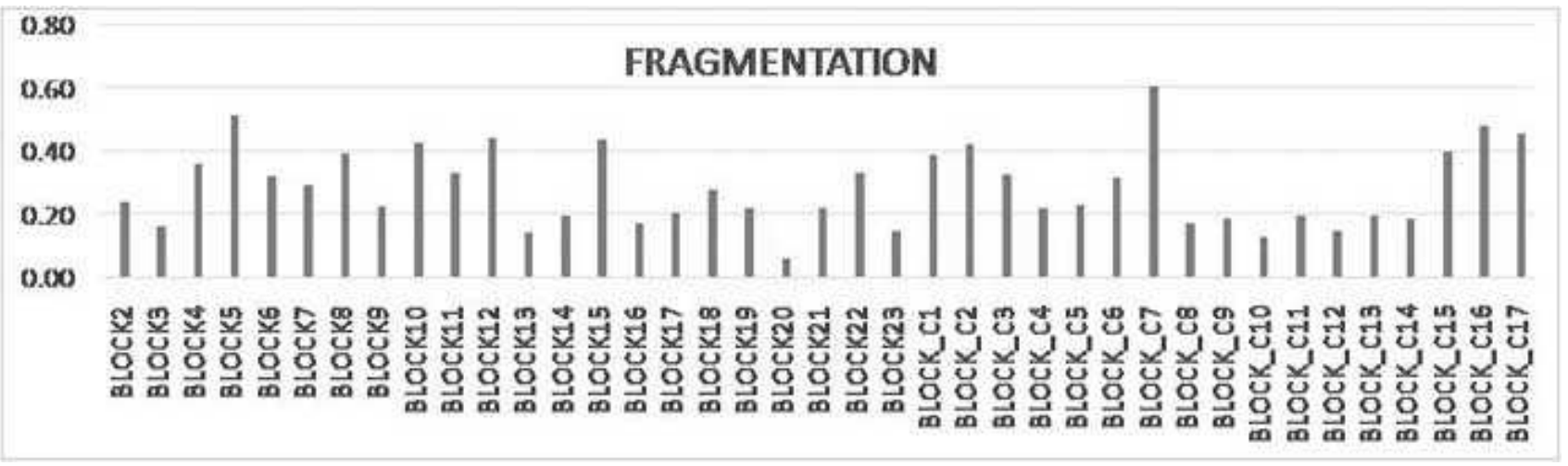

Figure 7. Plan of a Vernacular residence at ChinnaKanchi (Source: Author, 2018)

elements in the reconstructed facades and other modern facades of Kanchipuram. Since considerable changes are desired in the plan of a household for modern usage: the paper only examines the feasibility of adapting vernacular elements to the facades alone. The below listed parameters of vernacular elements and their degree of preference was obtained. They were analyzed using a multiple correlation matrix.
- Preference for socializing in a semi private space in front of the house

- Preference for semi private space configuration

- Preference on window sizes

- Preference on detailed decorations.

- Preference for parking configuration

- Preference for a window or balcony in the first floor

- Preference for a window or balcony configuration 
Table 2. Chart showing correlation among various parameters (Source: Author, 2018)

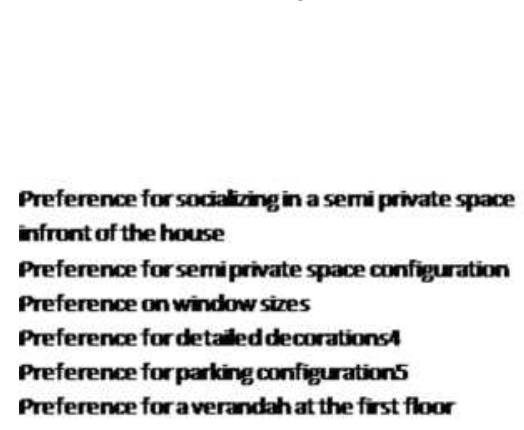

Preference for verandahconfigiration
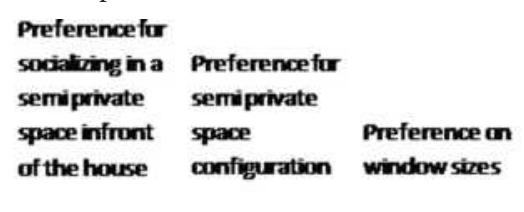

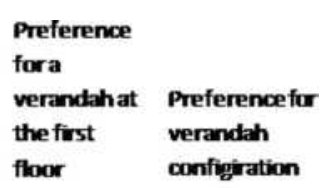

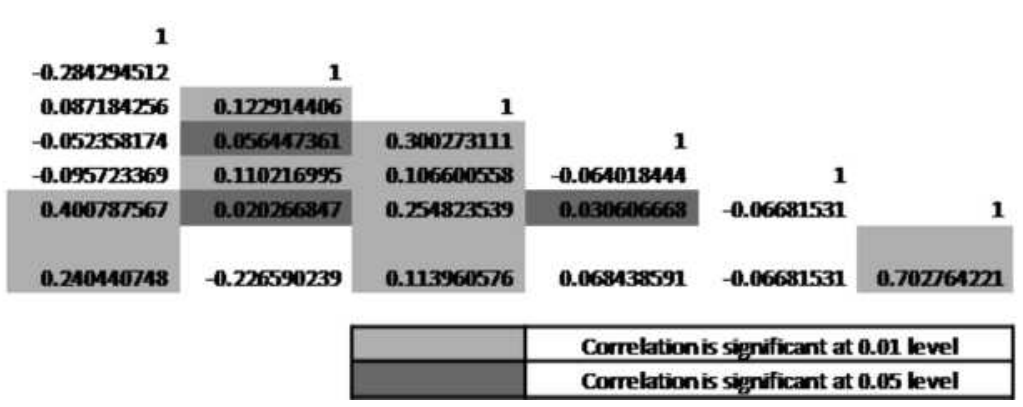

Most of the parameters had a correlation significant at 0.01 and a few correlation were significant at 0.05 also. 'Preference for socializing in semi-private space in front of the house' had a correlation significant at 0.01 level with two parameters 'preference for a verandah at the first floor' and preference for verandah configuration'. The parameter' preference on window sizes had a positive correlation with all the parameters. The correlation suggests the higher degree of preferences for vernacular elements and the preference for socializing also. The preference for detailed decorations was medium with $69 \%$ of the respondents opting for it.

\section{Discussion}

The study area comprising of the Periya Kanchi, Chinna Kanchi and the central stretch is predominantly of high dense built up area. The needs of the people, the place of workship, workplace (predominantly nearby), shops to procure basic needs are all located at the arms reach from the residences. The high relative density was observed in the map based analysis in major parts of the study area. The domestication of life increase the need to upkeep the present remnant set up of this traditional core. The domestication is culturally and spatially well pronounced as the residences are located around the temple. Kanchipuram celebrates some festival or the other for more than 300 days of an year of which major festivals falls within the study area.

Therefore the physical layout of the city is still intact in the residential areas around the temple owing to its cultural fervor. The context of the cultural patterns was at good fit with their form. The definition of form varies from settlement to the individual houses. The context is defined as all the programs/activities happening and which demands space in one way or the other. Hence the context and the form are mutually interdependent. A change in either one would cause a considerable impact on the other. These

explanations derived from Christopher Alexander 'synthesis of form' holds good in the case of Kanchipuram.

Given the aspects of the context and form which are unchanged the need to conserve the form aspects which are fastly facing a change is the need of the hour.

\subsection{Importance of Architecture and Planning of Kanchipuram}

The block level analysis brings out certain values and considerations. The blocks in Chinna Kanchi and Periya Kanchi are typical examples of blocks in the whole town of Kanchipuram. Other than the central commercial stretch the blocks and its tissues have not changed inspite of lot of reconstruction activities within the tissue. Most of the blocks have their long sides facing north east and south west. This orientation in observed in Periya Kanchi and other parts of Kanchipuram. In Chinna Kanchi the long sides face north and south orientation. The orientation is designed to capture the monsoon winds. The houses are characterized by one or more courtyards, clestorey windows to enhance ventilation through stack effect. Due to this orientation of the blocks east and west sun is avoided by common wall construction thereby avoiding heat gain. The blocks as an average has $23 \%$ open space which is centrally located in the blocks. These open spaces are the culmination of gardens in the back yard of each house. The average percentage of open space accounts to a ratio of 1:4 with the built up space. This configuration and ratio suggests that there could be a stack effect inducing ventilation at the block level also.

Considerably high block density, low variance and low fragmentation suggests that the blocks are compact, fine grained and homogeneous. The fine grain has been the suggested definition for urban coherence. It is considered as a pattern consisting of very small particles and having smooth and regular texture (Olgu, Bardia, 2018). 
According to Gestalt psychology, human cognitive processes used to follow a grouping integrity which featured proximity, similarity, good continuation, closure, symmetry and parallelism. According to this principle the variation in the building footprints could be used to show a certain sense of rhythm when the footprints are close to each other and share a similar size (Koffta, 2016). The above discussions bring out the value of town planning of Kanchipuram and its epitome. The above results lead to further subjective discussions. The facade in the street represents a continuousness which adds to a sense of enclosure. The socializing transitional space which amounts to $13 \%$ as an average in each block and which is an element of every unchanged vernacular building indicates softness in the urban fabric. Apart from containing a considerable percentage of space for socializing within the block, the streets do not offer severe restrictions to human interaction in the streets. The parking of vehicles in the road side and the domesticated traffic are the only hindering factors. However these aspects of the urban fabric are facing a change with the reconstruction activities within the tissues. The thinnai in the street front being a space to sit and interact contributes to sedibility of the urban fabric. Detractors which hinder the social life are the reconstruction and grill fencing of such spaces. The need for parking space would become a detractor if not effectively integrated into the tissue without affecting sedibility.

Apart from the block level parameters this sedibility factor is also a component of the individual houses and forms $1 / 6$ th of the total area. The social and climatic design elements and the space configuration follows a unique language in proportions and setting. It also offers a significant differentiation at the architectural level. Each house which is a part of the whole language is unique. Such differentiation could be achieved only if the design and construction activities are done by masons or architects who are very close or have a very good understanding of the social capital. Hence architecture and planning should have essentially been a part of the social capital of Kanchipuram. This social capital includes a set of social norms of conduct, knowledge, mutual obligation, expectations and trust (Andrea Colantanio and Tim Dixon, 2011). This epitome of secular architecture and planning needs to be conserved and changes optimized. The development leads have caused such a change. Gentrification and tourism development have the potential to displace historic communities. Developement divorced from its human and cultural context is growth without a soul (Amareswar Galla, 2016).Hence the way of development should include the intangibles along with the tangibles. The intangibles are traditions, communities and way of life. Such a development and responsible tourism can be economically complimenting to individuals, households and the nation.
Conserving the physical or the important tangible attribute can pave a great way towards complimenting various processes involved in the indigenous way of life. Hence the preference towards such a measure was quantified.

\subsection{Planning and the Endeavor of Conservation}

The rational top-down approach to planning lacked consideration of the psychological and social aspects of space. Conversely, the traditional living area - the place that we recognized as unplanned - has long been an important public space for city users, and contributes to the vitality of the city and the sense of community.In short, modernist planning neglects real situations and human factors (Kong in Wai, Michael Siua,b and Yi Hua Huang 2015).

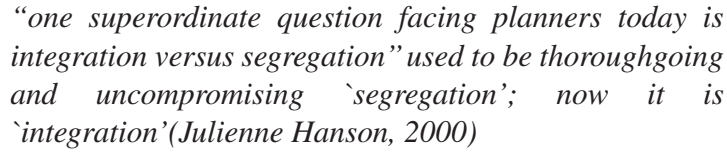

Therefore the paper suggests a planning approach which is participatory and which can resist the factors of inconveniences causing the change in the traditional urban fabric. Hence the process of conservation implementation could happen more efficiently when the professional intervention can play a role of preventing unwanted market tendencies. The process of conservation implementation is further conceptually described in this section of the paper. Periya Kanchi and Chinna Kanchi is a zone teeming with activity throughout the day. This indigenous fervor of functions in the inner cities of India is best described as below.

Hence the context of life process which involves these activities within and outside the households are best supported when the physical domain or the form supporting them are also indigenous. The protection does not only involve planning, but also a comprehensive endeavor (Jinghui Wang 2012). The comprehensive endeavor could be a set of phase wise processes supported by resource persons and resources. Architects and planners who are resource persons can be involved in the process of conservation with a longer commitment and being a part of the social capital. This process based, step by step, slow and steady method has been the necessary characteristic of vernacular architecture. The rigor of vernacular architecture is a resultant of such a process. Hence the planning methods for conservation should greatly draw lessons from the vernacular architecture. It should have ways of including local solutions. Social and cultural logics should be incorporated.

Such an approach to conservation ensures the bottom up approach in the true sense. The bombastic attitudes and interventions could be avoided. Instead a utilitarian and integral approach could be adopted. 
In nutshell the conservation activities can also be a part of social capital of Kanchipuram.

\subsection{Tourism Aspects if Heritage Conservation}

Heritage is the most modern phase of conservation. It is a concept that provides "the link between the preservation of the past for its intrinsic value, and as a resource for the modern community as a commercial activity (Ashworth and Tunbridge, 1900). Given this concept of commodification of heritage. Heritage as a commodity requires a consumer. Various approaches towards heritage conservation delineates tourists as the consumer which is subjected to a number of philosophical interpretation which is supportive of the notion.

However the approach towards heritage conservation presented in the paper presume traditional building materials and traditional skill associated with it as a product, to which the local residents of the town themselves are the consumers. However it requires considerable awareness generation for them to take up such a role. Tourism promotion activities also have a very good scope in Kanchipuram and it could be greatly complimentary. Tourist can actually have a perception of the value in its true sense; which is locally fully realized.

\section{Conclusion}

The traditional architecture and planning of Kanchipuram was expressed in its epitome. The wholesomeness and the ideal fit to its context was observed. The changes at the building level and tissue level effects the climax and aptness of the physical design. The changes have occurred to buildings as a whole, to building components and to the tissue of the settlements. The existing heritage buildings need to be conserved. A heritage cell could be established to control and regulate the changes. The heritage cell would provide or arrange necessary, fiscal, technical, and management support for conservation of the buildings.

Further to bring about the vernacular legacy into the new buildings and the reconstructed buildings the potential is ripe and need for action is abvious. Socializing in the city of Kanchipuram is not avoided however is been an unavailable practice. The need for awareness, a larger acceptance and availability of resources could considerably boost the implementation of heritage elements in modern facades of Kanchipuram. Changes in the facade can be a precursor to further changes in the larger fronts of the physical domain and in turn sustaining the way of life. The implementation of the conservation measures could be through intense planning activities. The planning activities could be largely participatory in approach and essentially a realized part of the social capital.

Hence the conservation of heritage at Kanchipuram should be a part and boon towards its social, environmental and economic betterment. The needs and quo of the individuals and families fully realized. The initiative would generate considerable employment opportunities for the masons, laborers and artisans with traditional skills.

\section{References}

Abakerli. S. (2012). Crafting India's Economic Growth and Development.

Amareswar Galla, (2016). Culture and Developement in New Urban Agenda: Learning from the Hoi and Amaravati, Special issue on Asia and Urban Heritage.

Amir Hossein Askari, and Kamariah Binti Dola, (2009). Influence of Building Façade Visual Elements on Its Historical Image: Case of Kuala Lumpur City, Malaysia

Amir Hossein Askari ${ }^{1 *}$, Soha Soltani², (2018). Contribution of Building Façades to Attractive Streetscapes: Study of Two Main Streets in Kuala Lumpur City

Andrea Colantanio and Tim Dixon, (2011), Urban regeneration and social Sustainability.John Wiley \& Sons.

Ashworth, Gregory J., and J. E. Tunbridge. (1990). The tourist-historic city. London: Belhaven..

Carin Combrinck, (2018). Socially responsive researchbased design in an architecture studio, Frontiers of Architectural Research.

Hamed Mohammadi Mazraeha, MahdiehPazhouhanfar, (2017). Effects of vernacular architecture structure on urban sustainability case study: Qeshm Island, Iran, Frontiers of Architectural Research.

Hong Kong, Kin Wai Michael Siu, a,b, and Yi Hua Huanga (2015). Everyday life under modernist planning: A study of an ever-transforming urban area in, Urban Design International .308

K. Koffka, (2013). Principles of Gestalt Psychology. Evanster, USA: Routledge.

Lino Bianco, (2017). Architecture, values and perception: Between rhetoric and reality, Frontiers of Architectural Research.

Minja Yang, (2016). Humanising the city: Trends in Asia Pacific, Special issue on Asia and Urban Heritage.

Mir Ahmad, Kashan, (2016). The Role of Physical Characteristics in Enhancing Social Interaction and Use of Urban Space (A case analysis of neighborhood center of Soltan) 
Murth,G.S and Bari (2012). Sense and the city - Dynamics of economics and culture.

Nany Yuliastuti*, Annisa Mu'awanah Sukmawati, Purwoningsih Purwoningsih, Utilization Of Social Facilities to Reinforce Social Interaction In Formal Housing

Olgu Caliskan, Bardia Mashhoodi, (2018). Urban Coherence: a morphological definition, research gate.

Olgu Caliskan, Bardia Mashhoodi, (2017). Urban Coherence A Morphological Definition, Urban Morphology International Seminar on Urban Form.

Rohit Jigasu, Gaima Jain, Anushree Deb (2013). Socio Economics of Urban Heritage
Sergio Porta, John Luciano Renne, (2005). Linking urban design to sustainability: formal indicators of social urban sustainability field research in Perth, Western Australia, URBAN DESIGN International.

UNESCO. (2010). Histoic Districts for all-India. New Delhi: UNESCO

Xin Li, Zhihan Lv, Ihab Hamzi Hijazi, Hongzan Jioa, Li Li, Kuncheng Li, (2016). Assessment of Urban Fabric for Smart Cities,IEEE Access.

YuanWang., (2012). Management of the Grand Canal and it's bid as a world cultural heritage site. Frontier of architectural research 37 . 